\title{
Gallium Ga 68-DOTANOC
}

National Cancer Institute

\section{Source}

National Cancer Institute. Gallium Ga 68-DOTANOC. NCI Thesaurus. Code C74034.

A gallium Ga 68-radiolabeled analogue of somatostatin that may be used in conjunction with positron emission tomography (PET) to image neuroendocrine tumors and metastases. Gallium Ga 68-DOTANOC is a conjug ate of the somatostatin analogue Nal3-octreotide (NOC) and gallium Ga 68-labeled 1,4,7,10-tetraazacyclododecane$\mathrm{N}, \mathrm{N}$ ',N",N"'-tetraacetic acid (DOTA). The somatostatin analogue NOC has a high affinity for somatostatin receptor subtypes 2, 3, and 5; these receptor subtypes have been shown to be present in large numbers on neuroendocrine tumors and their metastases, while most other normal tissues express low levels of these somatostatin receptor subtypes. 